\title{
Epidemiology and Treatment Outcomes of Testicular Germ Cell Tumor at Tertiary Care Center in Patna, India: A Retrospective Analysis
}

\author{
Dharmendra Singh ${ }^{1}$, Pritanjali Singh ${ }^{2}$, Avik Mandal ${ }^{3}$
}

Department of Radiotherapy, AIIMS, Patna, India.

\begin{abstract}
Background: Malignant testicular neoplasm constitutes about $1 \%$ of all cancers in male, but malignant germ cell tumors are most common tumors in adolescents and young adult males. In this study we report our experience of testicular germ cell tumors presenting at All India Institute of Medical Sciences, Patna, a tertiary referral centre, with respect to epidemiology, histopathology, management and outcome. Methods: This study was conducted in department of Radiotherapy, All India Institute of Medical Sciences, Patna from August 2014 to September 2019. It was single institution based retrospective study in which data was retrieved from the recorded files $\&$ analysed. The study focused on epidemiology and survival outcomes. Results: In this study we analysed, 38 histologically confirmed cases of testicular germ cell tumor. Seminoma and nonseminoma were 50\% (19) and $50 \%$ (19) respectively. The median age was 31 years. The most common affected age group was 31 to 40 years. Metastasis was present in $50 \%$ of patients at presentation. At diagnosis the stage III, II and I were found in $50 \%$, $28.9 \%$ and $21.1 \%$ respectively. Patients in good risk, intermediate risk and high risk were in $65.8 \%, 13.2 \%$ and $21.1 \%$ respectively. The median recurrence free survival (RFS) and overall survival (OS) was 52 months and 71 months respectively. Conclusion: Most of the cases presented with advanced stage and majority of them had undergone high inguinal orchidectomy. The high nodal burden disease at presentation was associated with partial response to standard chemotherapy. It seems that there is the need of alternative chemotherapy regimen especially in nonseminomatous germ cell tumors. Patients presenting with disease confined to locoregional lymph nodes or local disease showed good prognosis.
\end{abstract}

Keywords: Testicular germ cell tumor- prognosis- survival- male germ cell tumor

Asian Pac J Cancer Care, 5 (1), 45-50

Submission Date: 11/20/2019 Acceptance Date: 01/15/2020

\section{Introduction}

Malignant testicular neoplasm constitutes about $1 \%$ of all cancers in male [1], but malignant germ cell tumors (GCT) are most common tumors in adolescents and young adult males [2]. It has been seen that the incidence of testicular GCT has doubled in past 40 years [3]. India has the lowest incidence of testicular carcinoma that is about $1.7 \%$ [4]. Age standardized incidence in highest in New Zealand (7.8) followed by UK (6.3) and Australia (6.1) per 100000 men. Maldescended testis and cryptorchidism is the most common factor associated with testicular carcinoma, which increases the risk by 2-4 times [5]. GCTs are divided into seminoma and

nonseminoma as they present with distinct epidemiology, natural history, which ultimately guides to management strategies. The Western nations reported earlier stage at diagnosis while most of the Indian studies have reported advanced stage at presentation [6]. In this we report our experience of testicular germ cell tumors presenting at All India Institute of Medical Sciences, Patna, a tertiary referral centre, focussing on epidemiology, histopathology, management, outcomes and prognosis.

Aim

Aim of the study to evaluate epidemiology, treatment

Corresponding Author:

Dr. Dharmendra Singh

Department of Radiotherapy, AIIMS, Patna, India.

Email: babu.dsingh.singh35@gmail.com 
outcome, survival and prognosis.

\section{Materials and Methods}

This study was conducted in department of Radiotherapy, All India Institute of Medical Sciences, Patna from August 2014 to September 2019. It was single institution based retrospective study in which data was retrieved from the recorded files \& analysed after approval from Institutional Ethics Committee. The study focused on demographic profile as well as clinical presentation with respect to age, presenting complaints, histological types \& tumours markers, surgical procedures, systemic chemotherapy, toxicity and disease free and overall survival outcomes. Data retrieved included details of clinical presentation, examination findings, radiological details, per operative findings, post operative histopathological report, adjuvant treatment details, and tumor markers AFP (alpha fetoprotein), $\beta$ HCG ( $\beta$ Human chorionic gonadotropin), LDH (lactate dehydrogenase).

\section{Statistical analysis}

Statistical evaluation was done using SPSS version 25. Chi-square test and Kaplan Meier survival curves were plotted for recurrence free and overall survival. Recurrence free survival was defined as time from diagnosis till recurrence whereas overall survival was defined as time from diagnosis to death.

\section{Results}

In this study we analyzed 38 patients $(n=38)$, histologically confirmed cases of germ cell tumor, of which seminoma and nonseminoma were 50\% (19) and $50 \%$ (19) respectively. The median age of presentation was 31 years $(1-61)$. The most common affected age group was 31 to $40(31.6 \%)$ of the cases followed by age group of 21 to 30 years $(28.9 \%)$ and least number of cases $(7.9 \%)$ were seen in age group of $>50$ years. Eastern Cooperative Oncology Group Performance Status (ECOG PS) was 0 in $31.6 \%$ of patients, ECOG PS 1 in $39.5 \%$, ECOG PS 2 in $15.8 \%$ and ECOG PS 3 in $13.2 \%$. Testicular swelling was the most common symptom and seen in $71.1 \%$ of patients. Other presenting symptoms were abdominal pain, abdominal pain with lump, hemoptysis, neck node and sacral mass seen in 5.3\%, 5.3\%, 5.3\%, $7.9 \%$ and $5.3 \%$ respectively. Metastasis was observed in $50 \%$ of patients at initial work up, most common site of metastasis was lung $(26.3 \%)$, liver in $7.9 \%$, inguinal lymph nodes in $7.9 \%$ and supraclavicular lymph nodes in $7.9 \%$. Post operative staging revealed that $50 \%$ of patients were in stage III followed by stage II and stage I in $28.9 \%$ and $21.1 \%$ respectively. Seminoma presented most commonly in stage II $(21.1 \%)$ and non seminoma in stage III (34.2\%). The median tumor size was $6(3.2-12.3) \mathrm{cm}$. Upfront surgery was performed in $78.9 \%$ of cases and all consisted of high inguinal orchidectomy, $21.1 \%$ of cases were not able to undergo upfront surgery and these cases were considered for high inguinal orchidectomy after neoadjuvant chemotherapy.

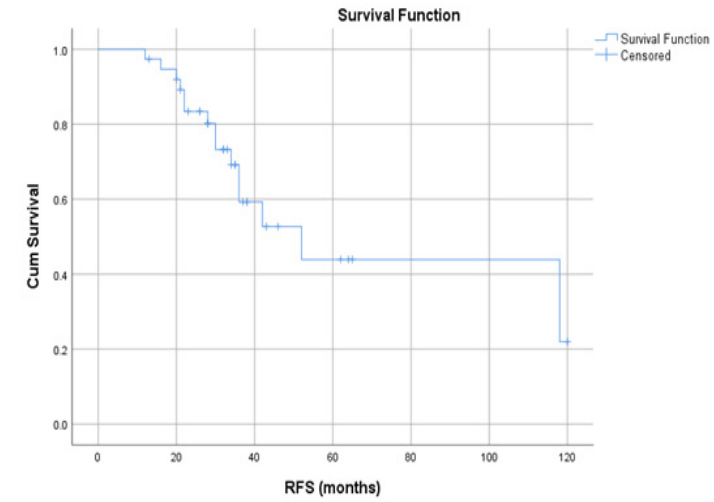

Figure 1. Recurrence Free Survival (RFS) in month

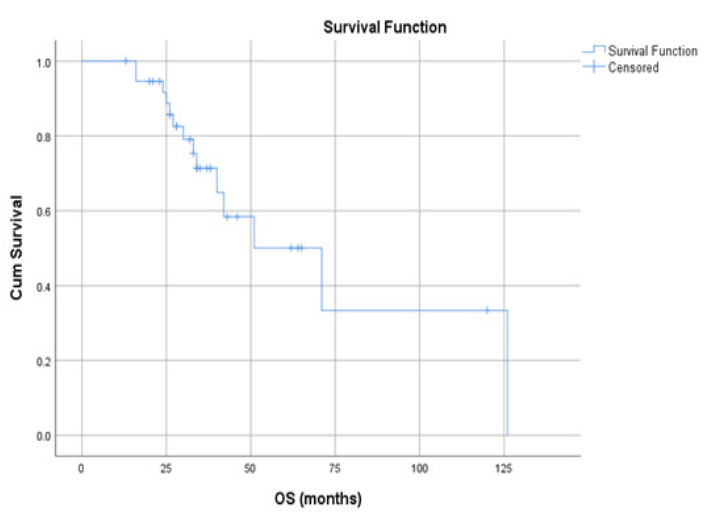

Figure 2. Overall Survival (OS) in month

As per International Germ Cell Consensus Classification (IGCCCG) classification risk group we found in this study that good risk, intermediate risk and high risk were in $65.8 \%, 13.2 \%$ and $21.1 \%$ respectively. Among the good risk patients, $28 \%$ having metastatic disease and $72 \%$ with local disease at presentation while $87.5 \%$ of high risk patients presented with metastatic disease and $12.5 \%$ with local disease. In this study serum tumor marker groups were S0, S1, S2 and S3 in 2.6\%, 60.5\%, 26.3\% and $10.5 \%$ respectively. We found that in seminoma the median value of AFP was $4 \mathrm{ng} / \mathrm{ml}(1.3-56), \beta \mathrm{HCG} 638$ $\mathrm{mIU} / \mathrm{ml}(246$ - 1200), LDH $486 \mathrm{U} / \mathrm{L}(212-1563)$ and in nonseminoma AFP was $380 \mathrm{ng} / \mathrm{ml}(0.5-1500), \beta \mathrm{HCG}$ $316 \mathrm{mIU} / \mathrm{ml}$ (1.0 - 69399), LDH $558 \mathrm{U} / \mathrm{L}$ (312 - 3261). The median volume of locoregional disease was $65 \mathrm{cc}$ in seminoma and $120 \mathrm{cc}$ in nonseminoma, these were measured on the basis of radiological parameters of largest locoregional lymph node from CT scan (Table 1) Response to chemotherapy after surgical intervention, showed that response evaluation criteria in solid tumors 1.1 (RECIST) of target lesion complete response (CR) in $15.8 \%$, partial response (PR) in $63.2 \%$ and radiological response could not be assessed in $21.1 \%$ of cases, similarly RECIST of non target lesion or of metastatic site were showing CR in $21.1 \%$, PR in $21.1 \%$ and stable disease in $5.3 \%$ while RECIST could not be evaluated in $50 \%$ of cases. Systemic chemotherapy was indicated in $94.7 \%$ and not indicated in only $5.3 \%$ of patients. Pre-chemotherapy pulmonary 
Table 1. Baseline Characteristics of testicular GCT

\begin{tabular}{lcccccccc}
\hline & \multicolumn{4}{c}{ Seminoma } & \multicolumn{5}{c}{ Nonseminoma } \\
& Mean & Max & Min & Median & Mean & Max & Min & Median \\
\hline Age (years) & 37 & 61 & 25 & 36 & 24 & 60 & 1 & 24 \\
Volume of locoregional disease & 288.43 & 1728.00 & .00 & 65.36 & 203.78 & 864.00 & .00 & 120.00 \\
Pre chemo AFP & 10.8 & 56.0 & 1.3 & 4.0 & 474.8 & 1500.0 & .5 & 380.0 \\
Pre chemo HCG & 640.7 & 1200.0 & 246.0 & 638.0 & 4953.2 & 69399.0 & 1.0 & 316.0 \\
Pre chemo LDH & 575 & 1563 & 212 & 486 & 891 & 3261 & 312 & 558 \\
Delay (days) & 7 & 24 & 0 & 5 & 7 & 20 & 0 & 9 \\
RFS (months) & 47 & 120 & 13 & 36 & 28 & 52 & 12 & 28 \\
OS (months) & 49 & 126 & 13 & 38 & 30 & 71 & 16 & 28 \\
\hline Pecre
\end{tabular}

Pre chemo - pre chemotherapy; AFP- alpha fetoprotein; HCG - $\beta$ Human chorionic gonadotropin; LDH - lactate dehydrogenase; RFS - recurrence free survival; OS - overall survival; volume of locoregional disease in cc

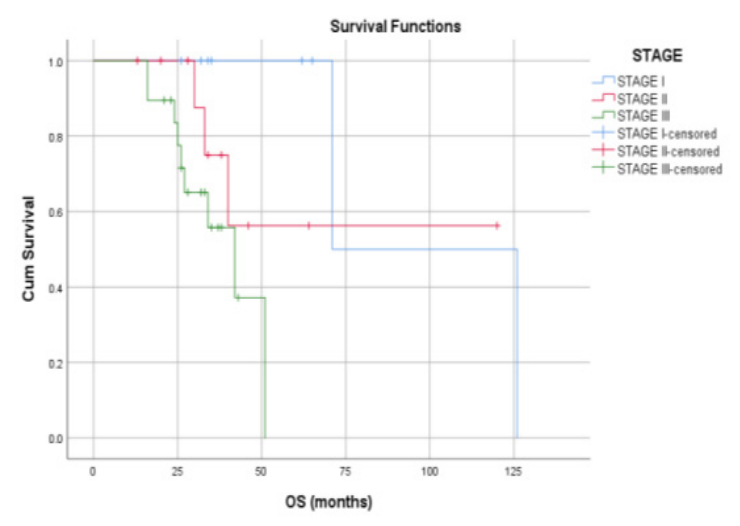

Figure 3. Overall Survival in Months of Male GCT Comparing to Stage; Log Rank (Mantel-Cox) $p=0.02$

function test (PFT) was done in $65.8 \%$ while status of PFT was not known in $23.7 \%$ and not performed in $10.5 \%$ of cases. Neoadjuvant chemotherapy was considered in $21.1 \%$ of cases and these are the patients not able to undergo upfront surgery. Adjuvant chemotherapy was not taken or defaulted by $18.4 \%$ of patients and $81.6 \%$ of patients completed their scheduled chemotherapy. Neutropenia was the most common complication followed by diarrhoea and pulmonary toxicity was least common. Grade III diarrhoea was seen in $8.7 \%$ of patients, grade III mucositis in $2.6 \%$, grade III neutropenia in $13.1 \%$, febrile neutropenia in $5.7 \%$, anaemia in $4.3 \%$ and pulmonary toxicity in $3.9 \%$ of patients respectively. Grade I or II complication of was seen in $22.3 \%$ of cases. Toxicities of the chemotherapy led to the delay in treatment schedule, $39.5 \%$ patients took their chemotherapy on schedule, $34.2 \%$ of patients were in delay in group of $1-10$ days, $21.1 \%$ were in delay group of 11-20 days and $5.3 \%$ were in delay group of 21-30 days. The median number chemotherapy cycles were 4 (4-6). Baseline epidemiological characteristics are given in Table 2 on the basis of (histological category) seminoma and non seminoma. In this study on Kaplan Meier survival analysis we found that median duration of recurrence free survival (RFS) was 52 months (95\% CI; 26.7 - 76.3 months) (Figure 1), duration of median overall survival (OS) was 71 months (95\% CI; 35.1 - 106.8) months (Figure 2), the OS rates at 1,3 and 5 years were $100 \%, 71.4 \%$ and $50.1 \%$ respectively. RFS rates at 1,3 and 5 years were $97.4 \%, 69.2 \%$ and $43.9 \%$. There was statistically significant differences in OS while comparing according to IGCCCG risk group (Log Rank; $p=0.017$ ), metastatic versus local disease (Log Rank; $p=0.008)$ stage of the disease (Log Rank; $p=0.02$ ) (Figure 3 ) and upfront surgery (Log Rank; $\mathrm{p}=0.001$ ) but there was no statistical significant difference while comparing histological types (Log Rank; $\mathrm{p}=0.108$ ). Similarly there was statistical significant difference in RFS as in risk group (Log Rank; $p=0.05$ ), metastatic disease (Log Rank; $p=0.03)$ and upfront surgery (Log Rank; $p=0.002)$ but there was no statistical significant difference in stage (Log Rank; $p=0.12$ ) (Figure 4), histological type (Log Rank; $\mathrm{p}=0.22$ ).

\section{Discussion}

There is a lack of recent data from India on epidemiology of germ cell tumor (GCT) except for few small series [7]. There is a recent publication on epidemiological study on GCT by Joshi et. al.[8]. In our study the median age of patients with seminoma and nonseminoma were 36 (25-61) and 24 (1-60) years respectively. Joshi et. al. found similar age distribution among the seminomatous and non seminomatous in their study as median age in seminoma and nonseminoma 39 and 28 years respectively [8]. Similar findings regarding

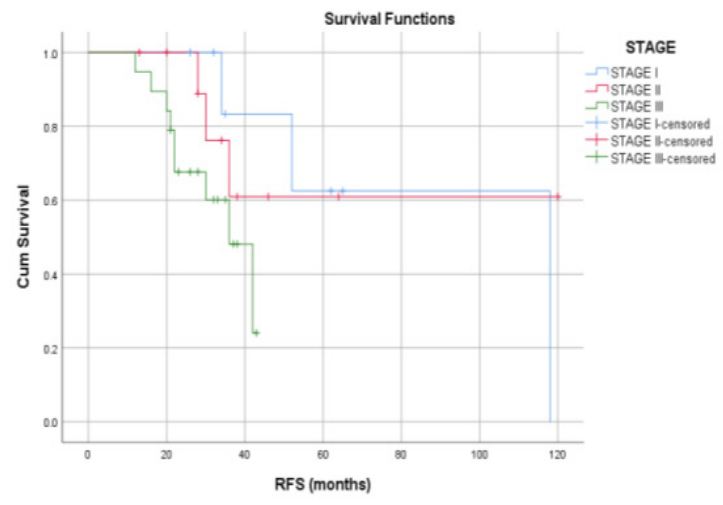

Figure 4. Recurrence Free Survival in Months of Male GCT Comparing to Stage; Log Rank (Mantel-Cox) $\mathrm{p}=0.102$ 
Table 2. Baseline Epidemiological Characteristics

\begin{tabular}{|c|c|c|c|c|c|c|}
\hline & & \multicolumn{2}{|c|}{ Seminoma } & \multicolumn{2}{|c|}{ Non-Seminoma } & \multirow[b]{2}{*}{$\begin{array}{l}\text { Chi- Square test } \\
\text { p value }\end{array}$} \\
\hline & & Count & Table N \% & Count & Table N \% & \\
\hline \multirow[t]{6}{*}{ Age group } & $1-10$ years & 0 & 0.0 & 4 & 10.5 & 0.029 \\
\hline & $11-20$ years & 0 & 0.0 & 4 & 10.5 & \\
\hline & $21-30$ years & 5 & 13.2 & 6 & 15.8 & \\
\hline & $31-40$ years & 9 & 23.7 & 3 & 7.9 & \\
\hline & $41-50$ years & 3 & 7.9 & 1 & 2.6 & \\
\hline & $>50$ years & 2 & 5.3 & 1 & 2.6 & \\
\hline \multirow[t]{4}{*}{ ECOG PS } & ECOG_0 & 8 & 21.1 & 4 & 10.5 & 0.221 \\
\hline & ECOG_1 & 6 & 15.8 & 9 & 23.7 & \\
\hline & ECOG_2 & 4 & 10.5 & 2 & 5.3 & \\
\hline & ECOG_3 & 1 & 2.6 & 4 & 10.5 & \\
\hline \multirow[t]{6}{*}{ Presenting complains } & Abdominal pain & 2 & 5.3 & 0 & 0.0 & 0.025 \\
\hline & Abdominal pain and lump & 0 & 0.0 & 2 & 5.3 & \\
\hline & Hemoptysis & 0 & 0.0 & 2 & 5.3 & \\
\hline & Neck node & 0 & 0.0 & 3 & 7.9 & \\
\hline & Sacral mass & 0 & 0.0 & 2 & 5.3 & \\
\hline & Testicular swelling & 17 & 44.7 & 10 & 26.3 & \\
\hline \multirow[t]{5}{*}{ Metastasis } & No metastasis & 13 & 34.2 & 6 & 15.8 & 0.097 \\
\hline & Inguinal lymph nodes & 2 & 5.3 & 1 & 2.6 & \\
\hline & Liver & 1 & 2.6 & 2 & 5.3 & \\
\hline & Lung & 3 & 7.9 & 7 & 18.4 & \\
\hline & Supraclavicular lymph nodes & 0 & 0.0 & 3 & 7.9 & \\
\hline \multirow[t]{2}{*}{ Metastatic disease } & Mets & 6 & 15.8 & 13 & 34.2 & 0.023 \\
\hline & Local disease & 13 & 34.2 & 6 & 15.8 & \\
\hline \multirow[t]{5}{*}{ RECIST non target lesion } & Complete response & 2 & 5.3 & 6 & 15.8 & 0.048 \\
\hline & Partial response & 2 & 5.3 & 6 & 15.8 & \\
\hline & Stable disease & 2 & 5.3 & 0 & 0.0 & \\
\hline & Not applicable & 0 & 0.0 & 1 & 2.6 & \\
\hline & Non metastatic disease & 13 & 34.2 & 6 & 15.8 & \\
\hline \multirow[t]{4}{*}{ RECIST target lesion } & Complete response & 3 & 7.9 & 3 & 7.9 & 0.717 \\
\hline & Partial response & 11 & 28.9 & 13 & 34.2 & \\
\hline & Stable disease & 0 & 0.0 & 0 & 0.0 & \\
\hline & $\begin{array}{l}\text { Response can't be assessed } \\
\text { (complete surgery) }\end{array}$ & 5 & 13.2 & 3 & 7.9 & \\
\hline \multirow[t]{4}{*}{ S group } & S0 & 0 & 0.0 & 1 & 2.6 & 0.107 \\
\hline & $\mathrm{S} 1$ & 14 & 36.8 & 9 & 23.7 & \\
\hline & $\mathrm{S} 2$ & 5 & 13.2 & 5 & 13.2 & \\
\hline & $\mathrm{S} 3$ & 0 & 0.0 & 4 & 10.5 & \\
\hline \multirow[t]{3}{*}{ Risk group } & Good & 17 & 44.7 & 8 & 21.1 & 0.003 \\
\hline & Intermediate & 2 & 5.3 & 3 & 7.9 & \\
\hline & High & 0 & 0.0 & 8 & 21.1 & \\
\hline \multirow[t]{3}{*}{ Surgical details } & Biopsy & 2 & 5.3 & 4 & 10.5 & 0.607 \\
\hline & Left high inguinal orchidectomy & 7 & 18.4 & 5 & 13.2 & \\
\hline & Right high inguinal orchidectomy & 10 & 26.3 & 10 & 26.3 & \\
\hline \multirow[t]{2}{*}{ Surgery was upfront } & Yes & 16 & 42.1 & 14 & 36.8 & 0.426 \\
\hline & No & 3 & 7.9 & 5 & 13.2 & \\
\hline \multirow[t]{2}{*}{ Stage } & Stage I & 5 & 13.2 & 3 & 7.9 & \\
\hline & Stage II & 8 & 21.1 & 3 & 7.9 & \\
\hline
\end{tabular}


Continued Table 2.

\begin{tabular}{|c|c|c|c|c|c|c|}
\hline & & \multicolumn{2}{|c|}{ Seminoma } & \multicolumn{2}{|c|}{ Non-Seminoma } & \multirow[b]{2}{*}{$\begin{array}{c}\text { Chi- Square test; } \\
\text { p value }\end{array}$} \\
\hline & & Count & Table N \% & Count & Table N \% & \\
\hline \multicolumn{7}{|l|}{ Stage } \\
\hline & Stage III & 6 & 15.8 & 13 & 34.2 & \\
\hline \multirow[t]{2}{*}{ Indication of chemotherapy } & Yes & 18 & 47.4 & 18 & 47.4 & 1 \\
\hline & No & 1 & 2.6 & 1 & 2.6 & \\
\hline \multirow[t]{3}{*}{ Pre chemotherapy PFT } & Yes & 12 & 31.6 & 13 & 34.2 & 0.361 \\
\hline & No & 1 & 2.6 & 3 & 7.9 & \\
\hline & Not known & 6 & 15.8 & 3 & 7.9 & \\
\hline \multirow[t]{2}{*}{ G-CSF use } & Yes & 13 & 34.2 & 17 & 44.7 & 0.111 \\
\hline & No & 6 & 15.8 & 2 & 5.3 & \\
\hline \multirow[t]{5}{*}{ Delay in days (group) } & Not applicable & 6 & 15.8 & 3 & 7.9 & 0.122 \\
\hline & $1-10$ days & 3 & 7.9 & 10 & 26.3 & \\
\hline & 11 - 20 days & 5 & 13.2 & 3 & 7.9 & \\
\hline & 21 - 30 days & 2 & 5.3 & 0 & 0.0 & \\
\hline & No delay & 3 & 7.9 & 3 & 7.9 & \\
\hline \multirow[t]{5}{*}{ Total number of cycles } & 0 & 6 & 15.8 & 3 & 7.9 & 0.167 \\
\hline & 1 & 0 & 0.0 & 1 & 2.6 & \\
\hline & 3 & 3 & 7.9 & 0 & 0.0 & \\
\hline & 4 & 4 & 10.5 & 4 & 10.5 & \\
\hline & 6 & 6 & 15.8 & 11 & 28.9 & \\
\hline \multirow[t]{2}{*}{ Died (event) } & Yes & 7 & 18.4 & 8 & 21.1 & 0.746 \\
\hline & No & 12 & 31.6 & 11 & 28.9 & \\
\hline \multirow[t]{2}{*}{ Recurrence } & Yes & 8 & 21.1 & 7 & 18.4 & 0.746 \\
\hline & No & 11 & 28.9 & 12 & 31.6 & \\
\hline
\end{tabular}

the median age at diagnosis was noted by A. A. Ghazarian et. al. as median age at diagnosis were 36 years and 28 years for seminoma and nonseminoma respectively [9]. In this study $50 \%$ of the cases were seminomatous and $50 \%$ of cases were non seminomatous GCT. ECOG performance status of patients in our study we found that seminomatous GCT presented most commonly in ECOG PS 0 and 1 while nonseminomatous GCT presented in ECOG 1, 2 and 3. Clinical presentation of seminomatous GCT were as testicular mass in $89.4 \%$ and $52.6 \%$ of the nonseminomatous GCT presented with testicular swelling and rest with symptoms of distant disease as supraclavicular metastasis, hemoptysis or abdominal lump. In this study seminomatous GCT with localized disease and metastatic disease were $34.2 \%$ and $15.8 \%$ respectively and nonseminomatous GCT with localized and metastatic disease were $15.8 \%$ and 34.2 respectively. This can also be represented as $31.5 \%$ of seminomatous and $68.4 \%$ of nonseminomatous presented with metastatic disease. Most of the cases of nonseminomatous GCT presented with metastases. Epidemiological study by Joshi et. al. found similar outcome in their study with $64 \%$ of metastatic presentation in nonseminomatous GCT and $22.2 \%$ of metastatic disease in seminomatous GCT. We found in our study that the largest median tumor size was $6 \mathrm{~cm}(3.2-12)$ for seminoma and $6 \mathrm{~cm}$ (4-12.3) nonseminoma. For seminoma and non-seminoma, the largest median tumor size was $5.6 \mathrm{~cm}$ among black men and $5.7 \mathrm{~cm}$ among American populations as shown by A. A. Ghazarian et. al. in their study [9]. In this study we found that median pre-chemotherapy value of AFP, HCG and LDH in seminomatous GCT were $4 \mathrm{ng} / \mathrm{ml}, 638 \mathrm{mIU} / \mathrm{ml}$ and $212 \mathrm{U} / \mathrm{L}$ respectively. The median pre-chemotherapy value of AFP, $\beta \mathrm{HCG}$ and $\mathrm{LDH}$ in nonseminomatous GCT were $380 \mathrm{ng} / \mathrm{ml}, 316 \mathrm{mIU} / \mathrm{ml}$ and $558 \mathrm{U} / \mathrm{L}$ respectively. We found in our study that tumor markers $\mathrm{S}$ group as $\mathrm{S} 0, \mathrm{~S} 1$, $\mathrm{S} 2$ and $\mathrm{S} 3$ were $0 \%, 73.6 \%, 21 \%$ and $5.2 \%$ respectively in seminomatous GCT while in nonseminomatous GCT S0, S1, S2 and S3 were 5.2\%, 47.3\%, 26.3\% and $21 \%$ respectively. The serum tumor markers $\mathrm{S}$ group results were different from the findings of the study by Joshi et. al. [8]. Assessment of response to chemotherapy according to RECIST 1.1 we found that seminomatous GCT were showing CR, PR and SD in $15.7 \%, 57.8 \%$ and $0 \%$ respectively while response could not be assessed in $26.3 \%$. In case of nonseminomatous GCT CR, PR and SD were $15.7 \%, 68.4 \%$ and $0 \%$ while response could not be assessed in $15.7 \%$. The overall CR, PR and SD were $15.8 \%, 63.2 \%$ and $0 \%$ respectively and assessment could not be done in $21.1 \%$. This response rate is very low in compared to reports from other studies showing response upto $95 \%$ with systemic chemotherapy [10]. This may be due to delayed presentation with high nodal burden disease and most cases associated with poor risk factors. 
Classifying the cases on the basis of risk factor we found that good risk, intermediate risk and high risk cases were $65.8 \%, 13.2 \%$ and $21.1 \%$ respectively. It was found in this study that Good risk patients having metastatic disease in $28 \%$ and $72 \%$ with local disease while $87.5 \%$ of high risk presented with metastatic disease and $12.5 \%$ with local disease. Cost et. al. In their study found that $60 \%$ of the high risk patients presented with metastases [11]. We found in our study that upfront surgery (high inguinal orchidectomy) was done in $78.9 \%$ of cases and, $21.1 \%$ of cases were not able to undergo upfront surgery, Saju S V et. al. in their study observed that $91 \%$ of their patients underwent upfront surgery and only $9 \%$ considered for biopsy [12] this difference may be attributable to delay presentation at tertiary care center. All patients in our study received first line chemotherapy as bleomycin, etoposide and cisplatin (BEP) based regimen. In this study Neutropenia was the most common complication followed by diarrhoea and pulmonary toxicity was least common. Grade III or IV diarrhoea, mucositis, neutropenia and febrile neutropenia was seen in $8.7 \%, 2.6 \%, 13.1 \%$, and $5.7 \%$. Anaemia in $4.3 \%$ and pulmonary toxicity in $3.9 \%$ of patients while $22.3 \%$ of patients developed grade I or II chemotherapy related complications. Joshi et. al. in their study reported grade III or IV non hematological toxicity in $18 \%$ of cases, grade III or IV hematological toxicity in $18 \%$ of cases and febrile neutropenia in $20 \%$ of cases. This difference may be due to prophylactic use of granulocyte colony stimulating factors (GCSF) in $78.9 \%$ in our study but prophylactic GCSF was not used in study by Joshi et. al. [8]. In this study Kaplan Meier survival analysis RFS rates at 1,3 and 5 years were $97.4 \%, 69.2 \%$ and $43.9 \%$ respectively with median duration of RFS of 52 months (95\% CI; 26.7 - 76.3 months). The median overall survival (OS) was 71 months $(95 \% \mathrm{CI} ; 35.1-106.8)$. The OS rates at 1,3 and 5 years were $100 \%, 71.4 \%$ and $50.1 \%$ respectively. Saju S V et. al. in their study observed 3 year RFS and OS $73.5 \%$ and $80.3 \%$ respectively, this findings were almost consistent with our study [12].

In conclusion, testicular germ cell tumor is predominantly a disease of young adults and it presents as a testicular mass in almost all cases for which consultation to physician was sought. Most of the cases presented with advanced stage and majority of them have undergone high inguinal orchidectomy which is the standard surgical procedure for testicular germ cell tumor. The high nodal burden disease presentation at our center and most of the patient showed partial response to standard chemotherapy it seems that there is the need of alternative chemotherapy regimen in expectation to good response especially in nonseminomatous germ cell tumors to achieve complete response. Patients presented with disease confined to locoregional lymph nodes or local disease having good prognosis as compared to metastatic disease which was reflected in both recurrence free survival and overall survival. Overall survival in our study was not matching to the data of western studies the reason for this may be advanced disease at presentation, bulky retroperitoneal nodal disease, treatment abandonment, failure to maintain dose intensity and lost to proper follow up.

\section{Acknowledgments}

We acknowledge the help extended by the Department of Oncosurgery, AIIMS, Patna.

\section{Footnote}

Conflicts of Interest: The authors have no conflicts of interest to declare.

\section{References}

1. Vasdev N, Moon A, Thorpe AC. Classification, epidemiology and therapies for testicular germ cell tumours. Int J Dev Biol 2013; 57: 133-9.

2. Siegel R, Naishadham D, Jemal A. Cancer statistics, 2013. CA Cancer J Clin. 2013;63:11-30.

3. Huyghe E, Matsuda T, Thonneau P. Increasing incidence of testicular cancer worldwide: A review. J Urol 2003;170:5-11.

4. Shanmugalingam T, Soultati A, Chowdhury S, Rudman S, Van Hemelrijck M. Global incidence and outcome of testicular cancer. ClinEpidemiol 2013;5:417-27.

5. Boyle P, Zaridze DG. Risk factors for prostate and testicular cancer. Eur J Cancer 1993;29A:1048-55.

6. Stevenson SM, Lowrance WT. Epidemiology and diagnosis of Testis cancer. Urol Clin N Am Testicular Cancer 2015;42:269-73.

7. Bhutani M, Kumar L, Seth A, Thulkar S, Vijayaraghavan M, Kochupillai V.Germ cell tumours of the testis: Clinical features, treatment outcome and prognostic factors. Natl Med J India 2002;15:18-21

8. Joshi A, Zanwar S, Shetty N, Patil V, Noronha V, Bakshi G, Prakash G, Menon S, Prabhash K Indian Journal of Cancer; Epidemiology of male seminomatous and nonseminomatous germ cell tumors and response to first-line chemotherapy from a tertiary cancer center in India DOI: 10.4103/0019509X.197741

9. A. A. Ghazarian, B. Trabert, S. S. Devesa and K. A. McGlynn; Andrology; Recent trends in the incidence of testicular germ cell tumors in the United States 2015, 3, 13-18; doi: 10.1111/andr.288

10. de Wit R, Roberts JT, Wilkinson PM, de Mulder PH, Mead GM, Fosså SD, et al. Equivalence of three or four cycles of bleomycin, etoposide, and cisplatin chemotherapy and of a 3- or 5-day schedule in good-prognosis germ cell cancer: A randomized study of the European Organization for Research and Treatment of Cancer Genitourinary Tract Cancer Cooperative Group and the Medical Research Council. J Clin Oncol 2001;19:1629-40.

11. N. G. Cost, J. D. Lubahn, M. Adibi et al., "Risk stratification of pubertal children and postpubertal adolescents with clinical stage I testicular nonseminomatous germ cell tumors," Journal of Urology, vol. 191, no. 5, pp. 1485-1490, 2014.

12. S. V. Saju, Venkatraman Radhakrishnan, Trivadi S. Ganesan, Manikandan Dhanushkodi, Ganesarajah Selvaluxmy, Tenali Gnana Sagar; Factors that impact the outcomes in testicular germ cell tumors in low-middle-income countries Medical Oncology (2019) 36:28; https://doi.org/10.1007/s12032019-1252-6

\section{(c) (i) ()}

This work is licensed under a Creative Commons AttributionNon Commercial 4.0 International License. 